Tropical Journal of Pharmaceutical Research October 2021; 20 (10): 2127-2133

ISSN: $1596-5996$ (print); 1596-9827 (electronic) (C) Pharmacotherapy Group, Faculty of Pharmacy, University of Benin, Benin City, 300001 Nigeria.

\title{
Design, synthesis and cytotoxic evaluation of 2-amino-4- aryl-6-substituted pyridine-3,5-dicarbonitrile derivatives
}

\begin{abstract}
Amr S Abu Lila1,2*, Marwa H Abdallah ${ }^{1,2}$, El-Sayed Khafagy ${ }^{3,4}$, Tamer M Shehata ${ }^{5}$, Mahmoud S Soliman ${ }^{1,6}$, Kareem M Younes ${ }^{7}$, Mohamed Omran ${ }^{4}$, Shadeed Gad ${ }^{4}$

${ }^{1}$ Department of Pharmaceutics, College of Pharmacy, University of Hail, Hail 81442, Saudi Arabia, ${ }^{2}$ Department of Pharmaceutics and Industrial Pharmacy, Faculty of Pharmacy, Zagazig University, Zagazig 44519, Egypt, ${ }^{3}$ Department of Pharmaceutics, College of Pharmacy, Prince Sattam Bin Abdulaziz University, Al-kharj 11942, Saudi Arabia, ${ }^{4}$ Department of Pharmaceutics and Industrial Pharmacy, Faculty of Pharmacy, Suez Canal University, Ismailia 41552, Egypt, ${ }^{5}$ Department of Pharmaceutical Sciences, College of Clinical Pharmacy, King Faisal University, Alhofuf, Al-Ahsa 31982, Saudi Arabia, ${ }^{6}$ Department of Pharmaceutics and Industrial Pharmacy, Faculty of Pharmacy, Al-Azhar University, Cairo 11651, Egypt, ${ }^{7}$ Department of Pharmaceutical Chemistry, College of Pharmacy, University of Hail, Hail 81442, Saudi Arabia
\end{abstract}

*For correspondence: Email: a.abulila@uoh.edu.sa; Tel: +966-565-434-262

\begin{abstract}
Purpose: To synthesize novel pyridine derivatives and evaluate their efficiency as potent inhibitors of cyclin dependent kinase 2 (CDK2) enzyme for cancer therapy.

Methods: Pyridine scaffold were synthesized using one-pot multicomponent condensation reaction of arylidine with different primary amines. The cytotoxic potential of the new compounds was assessed using various cell lines. Furthermore, molecular docking studies based on the crystal structure of CDK2 was carried out to determine the possible binding modes that influence the anticancer activities.

Results: The results indicate that one-pot multicomponent reaction generated a series of functionalized pyridines with good yield. In vitro cytotoxicity study revealed superior cytotoxicity of the designed compounds against prostate and cervical cancer cell lines compared to 5-fluorouracil (standard anticancer compound) with half-maximal inhibitory concentration (IC50) values of $0.1-0.85$ and 1.2 $74.1 \mu \mathrm{M}$, respectively. Finally, molecular modeling simulation of the newly synthesized compounds showed that they fit well and are stabilized into CDK2 active site via hydrogen bonding and hydrophobic interactions.

Conclusion: The results indicate that the newly synthesized pyridine can exert potent anticancer activity presumably via inhibition of CDK2. However, this will need to be confirmed in in vivo studies.
\end{abstract}

Keywords: 5-Fluorouracil, Anticancer activity, Cyclin dependent kinase 2, Molecular docking, One-pot multicomponent reaction, Pyridine scaffold

This is an Open Access article that uses a funding model which does not charge readers or their institutions for access and distributed under the terms of the Creative Commons Attribution License (http://creativecommons.org/licenses/by/4.0) and the Budapest Open Access Initiative (http://www.budapestopenaccessinitiative.org/read), which permit unrestricted use, distribution, and reproduction in any medium, provided the original work is properly credited.

Tropical Journal of Pharmaceutical Research is indexed by Science Citation Index (SciSearch), Scopus, International Pharmaceutical Abstract, Chemical Abstracts, Embase, Index Copernicus, EBSCO, African Index Medicus, JournalSeek, Journal Citation Reports/Science Edition, Directory of Open Access Journals (DOAJ), African Journal Online, Bioline International, Open-J-Gate and Pharmacy Abstracts

\section{INTRODUCTION}

The development of Cyclin-dependent kinases (CDKs) inhibitors has sparked a lot of interest over the last two decades. This interest stemmed from the crucial roles of CDKs in regulating cellcycle progression [1,2]. Cyclin-dependent kinase2 (CDK2) is a member of protein kinase family 
that regulates cell cycle progression $[2,3]$. Overexpression of CDK2 has been linked to poor prognosis in a variety of cancer cells [4-6]. Accordingly, CDK2 could be considered as a potential therapeutic target for cancer treatment.

Pyridine scaffold is gaining increased attention in modern pharmaceuticals with pyridine-containing compounds possessing multiple biological activities such as antimalarial [7], antiviral [8], anticholinesterase [9], antidiabetic [10] and antimicrobial activities [11]. Most interestingly, pyridine derivatives have been reported to exert potent cytotoxic effects against a variety of cancer cell lines, such as leukemia, colon, and ovarian cancer cell lines [9,12,13]. Byth et al [14] synthesized imidazo[1,2-a] pyridine derivatives as plausible CDK2 inhibitors and investigated their activities against breast cancer cell line (MCF-7). The synthesized pyridine derivatives showed potent CDK2 inhibitory activity as well as anti-carcinogenic activity even at lower concentrations ranging from 0.004 to $0.046 \mathrm{M}$.

Recently, a one-pot multicomponent reaction using readily accessible primary amines, malononitrile and aromatic aldehydes in the presence of different Lewis acids such as $\mathrm{FeCl}_{3}$, $\mathrm{ZnCl} 2$, and $\mathrm{AlCl}_{3}$ has been adopted for the synthesis of substituted pyridines [15]. This multicomponent reaction generated a series of functionalized pyridines with good yield using catalyst and solvent-free conditions under the fusion condition. In the current study, we synthesized novel pyridine compounds through single-pot multi-component condensation reactions of arylidine and various primary amines. FTIR, ${ }^{1} \mathrm{H}$ NMR and mass spectroscopy were adopted for chemical characterization of the obtained pyridine derivatives. In vitro antitumor activity was also evaluated against a series of human cancer cells. Finally, virtual docking simulations were conducted to define the binding modes of the synthesized compound within the CDK2 active site. The results revealed that the synthesized pyridine derivatives fit well into CDK2 active site, and could represent novel CDK2 inhibitors with promising anti-proliferative activity against cancer cell lines; particularly, human prostate and cervical cancer cell lines.

\section{EXPERIMENTAL}

\section{General}

All reagents and chemicals were obtained from Sigma-Aldrich (St. Louis, MO, USA) and were utilized without further purification unless mentioned otherwise.

Gallenkamp melting point apparatus (Gemini BV., Apeldoorn, Netherland) was used to measure the melting points. Pye-Unicam SP 3300 spectrophotometer (Cambridge, UK) was utilized to record the FTIR spectra. A Varian Mercury VX-300 MHz spectrometer was employed to measure the ${ }^{1} \mathrm{H}-\mathrm{NMR}$ spectra. The mass spectra were detailed on GCMS-QP 1000 EX Shimadzu mass spectrometer (Shimadzu Corporation, Kyoto, Japan) at $70 \mathrm{eV}$.

\section{Synthesis}

A one-pot multicomponent reactions were adopted for the synthesis of 2-Amino-4-Aryl-6substituted pyridine-3,5-dicarbonitrile derivatives (S1-S4), as previously reported [15]. Briefly, a mixture of $0.06 \mathrm{~mol}$ arylidine, $0.069 \mathrm{~mol}$ of various primary amines (ethylamine, p-toluidine, aniline or a nucleophilic ammonium acetate) and anhydrous $\mathrm{ZnCl}_{2}(0.09 \mathrm{~mol})$ was agitated for $5 \mathrm{~h}$ at $80{ }^{\circ} \mathrm{C}$ in dry ethanol $(20 \mathrm{ml})$ and then filtered. The residue from ethanol, then methanol, was recrystallized. The synthesis method of the target compounds is depicted in Scheme 1 and Table 1.

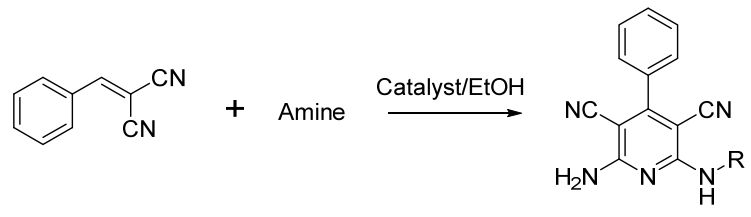

Scheme 1: Synthesis scheme for 2-amino-4-aryl-6substituted pyridine-3,5-dicarbonitrile derivatives

Table 1: Chemical compounds (S1-S4)

\begin{tabular}{ccccc}
\hline Compound code & Amine & Chemical formula & Mol wt \\
\hline $\mathrm{S} 1$ & $\mathrm{CH}_{3} \mathrm{CH}_{2} \mathrm{NH}_{2}$ & $\mathrm{C}_{15} \mathrm{H}_{13} \mathrm{~N}_{5}$ & 263 \\
$\mathrm{~S} 2$ & & $\mathrm{C}_{20} \mathrm{H}_{15} \mathrm{~N}_{5}$ & \\
S3 & & $\mathrm{C}_{13} \mathrm{H}_{9} \mathrm{~N}_{5}$ & 235 \\
& & $\mathrm{C}_{19} \mathrm{H}_{13} \mathrm{~N}_{5}$ & 311 \\
\end{tabular}


Synthesis of 2-Amino-6-(ethylamino)-4phenylpyridine-3,5-dicarbonitrile (S1)

A mixture of arylidine $(0.06 \mathrm{~mol})$, ethylamine as a nucleophile $(0.069 \mathrm{~mol})$ and anhydrous $\mathrm{ZnCl}_{2}$ $(0.09 \mathrm{~mol})$ in dry ethanol $(20 \mathrm{~mL})$ then solution was stirred for $5 \mathrm{~h}$ at $80{ }^{\circ} \mathrm{C}$. The formed precipitate was filtered and crystallized from ethanol, and then methanol with yield of $94 \%$. Melting point: $226{ }^{\circ} \mathrm{C},{ }^{1} \mathrm{H}-\mathrm{NMR}$ (DMSO-d 6 ) $\delta$ (ppm): 7.43-7.52 (5H, m, Ar-H), $7.23(4 \mathrm{H}, \mathrm{s}$, $\left.\mathrm{NH}_{2}\right)$, FT-IR $\left(\mathrm{cm}^{-1}\right): 1623(\mathrm{C}=\mathrm{N}), 2225(\mathrm{C} \equiv \mathrm{N})$, 2978 (C-H, aliphatic), 3108 (N-H), MS: $\mathrm{m} / \mathrm{z}: 263.3$ calculated for $\mathrm{C}_{15} \mathrm{H}_{13} \mathrm{~N}_{5}$.

\section{Synthesis of 2-Amino-4-phenyl-6-(p- tolylamino) pyridine-3,5-dicarbonitrile (S2)}

A mixture of arylidine $(0.06 \mathrm{~mol}), \mathrm{p}$-toluidine as a nucleophile $(0.069 \mathrm{~mol})$ and anhydrous $\mathrm{ZnCl}_{2}$ $(0.09 \mathrm{~mol})$ in dry ethanol $(20 \mathrm{~mL})$ then solution was stirred for $5 \mathrm{~h}$ at $80{ }^{\circ} \mathrm{C}$. The formed precipitate was filtered and crystallized from ethanol, and then methanol with yield of $91 \%$. Melting point: $258{ }^{\circ} \mathrm{C},{ }^{1} \mathrm{H}-\mathrm{NMR}$ (DMSO-d 6 ) $\delta$ (ppm): $2.26\left(3 \mathrm{H}, \mathrm{s}, \mathrm{CH}_{3}\right), 7.09-7.54(9 \mathrm{H}, \mathrm{m}, \mathrm{Ar}-$ $\mathrm{H}), 7.49\left(2 \mathrm{H}, \mathrm{s}, \mathrm{NH}_{2}\right), 9.02(1 \mathrm{H}, \mathrm{s}, \mathrm{NH}), \mathbf{F T}-\mathrm{IR}$ $\left(\mathrm{cm}^{-1}\right): 1630(\mathrm{C}=\mathrm{N}), 2208(\mathrm{C} \equiv \mathrm{N}), 3108(\mathrm{~N}-\mathrm{H})$, MS: $\mathrm{m} / \mathrm{z}: 325.1$ calculated for $\mathrm{C}_{20} \mathrm{H}_{15} \mathrm{~N}_{5}$.

\section{Synthesis of 2,6-Diamino-4-phenylpyridine- 3,5-dicarbonitrile (S3)}

A mixture of arylidine $(0.06 \mathrm{~mol})$, ammonium acetate as a nucleophile $(0.069 \mathrm{~mol})$ and anhydrous $\mathrm{ZnCl}_{2}(0.09 \mathrm{~mol})$ in dry ethanol $(20$ $\mathrm{mL}$ ) then solution was stirred for $5 \mathrm{~h}$ at $80{ }^{\circ} \mathrm{C}$. The formed precipitate was filtered and crystallized from ethanol, and then methanol with yield of $93 \%$. Melting point: $292{ }^{\circ} \mathrm{C},{ }^{1} \mathrm{H}-\mathrm{NMR}$ (DMSO-d 6 ) $\delta$ (ppm): 7.23 (4H, s, $\mathrm{NH}_{2}$ ), 7.43-7.52 $(5 \mathrm{H}, \mathrm{m}, \mathrm{Ar}-\mathrm{H}), \mathrm{FT}-\mathrm{IR}\left(\mathrm{cm}^{-1}\right): 1623(\mathrm{C}=\mathrm{N}), 2206$ $(\mathrm{C} \equiv \mathrm{N}), \quad 3363-3424 \quad(\mathrm{~N}-\mathrm{H}), \quad$ MS: $\mathrm{m} / \mathrm{z}: 235.3$ calculated for $\mathrm{C}_{13} \mathrm{H}_{9} \mathrm{~N}_{5}$.

Synthesis of 2-Amino-4-phenyl-6-(phenylamino) pyridine-3,5-dicarbonitrile (S4)

A mixture of arylidine $(0.06 \mathrm{~mol})$, aniline as a nucleophile $(0.069 \mathrm{~mol})$ and anhydrous $\mathrm{ZnCl}_{2}$ $(0.09 \mathrm{~mol})$ in dry ethanol was carried out without stirring at higher temperature. The formed precipitate was filtered and crystallized from ethanol, and then methanol with yield of $90 \%$. Melting point: $251{ }^{\circ} \mathrm{C},{ }^{1} \mathrm{H}-\mathrm{NMR}$ (DMSO-d 6 ) $\delta$ (ppm): $7.64\left(2 \mathrm{H}, \mathrm{s}, \mathrm{NH}_{2}\right), 7.05-7.56(10 \mathrm{H}, \mathrm{m}, \mathrm{Ar}-$ $\mathrm{H}), 910(1 \mathrm{H}, \mathrm{s}, \mathrm{NH}), \mathbf{F T}-\mathrm{IR}\left(\mathrm{cm}^{-1}\right): 1630(\mathrm{C}=\mathrm{N})$, $2208 \quad(\mathrm{C} \equiv \mathrm{N}), \quad 3155 \quad(\mathrm{~N}-\mathrm{H}), \quad$ MS: $\quad \mathrm{m} / \mathrm{z}: 311.1$ calculated for $\mathrm{C}_{19} \mathrm{H}_{13} \mathrm{~N}_{5}$.

\section{In vitro cytotoxicity studies}

\section{Tumor cell line}

Human lung cancer cell line (A549) was kept in DMEM High Glucose (4.5 g/L), with stable LGlutamine, and Sodium Pyruvate (Biowest, MO, USA). Human breast adenocarcinoma (MCF-7, and MDA-MB-231), hepatocellular carcinoma (HepG2), human prostate cancer (PC3) and Cervical cancer (Hela) were kept in RPMI-1640 medium with L-Glutamine (Lonza SPRL, Verviers, Belgium). Both media were supplemented with $10 \%$ FBS (Seralab, UK) and $1 \%$ antibiotic-antimycotic (Biowest, MO, USA). All cell lines were incubated under standard conditions $\left(37^{\circ} \mathrm{C}, 5 \% \mathrm{CO}_{2}\right)$.

\section{Evaluation of cell proliferation}

MTT tetrazolium assay was employed to assess the cytotoxic potential of the tested compounds on various cancer cell lines [16]. First, in a 96well plate, $100 \mu \mathrm{L}$ cell suspension corresponding to $1 \times 10^{4}$ cells/well were seeded and incubated for $24 \mathrm{~h}$. Serial dilutions of tested compounds in dimethyl sulfoxide (DMSO) (ranging from 0.1 to $100 \mu \mathrm{M}$ ) were prepared. At $24 \mathrm{~h}$ post incubation, spent culture medium was replenished with a fresh medium containing the specified serial dilutions of tested compounds. The cells were further incubated for $48 \mathrm{~h}$ and cell viability was estimated by the MTT assay as described previously [16]. A microplate reader (TEKAN Japan, Kanagawa, Japan) was used to measure the absorbance of each well at $570 \mathrm{~nm}$. The percent viable cells were plotted against tested compound concentration to determine the $\mathrm{IC}_{50}$ values summarized in Table 2.

\section{Molecular docking}

X-ray crystal structure of the molecular target along with its co-crystallized ligand was downloaded from the RCSB protein data bank (http://www.rcsb.org) with PDB code 1DI8. Chemsketch software was used to draw the molecular structures of the tested compounds and VEGAZZ software was used to calculate energy minimization of the tested compounds [17].

The molecular target was prepared for docking via Auto Dock Tools by removal of water molecules and heteroatoms followed by addition of hydrogen atoms and charge assignment. Search space for docking was defined by a grid box of appropriate dimensions placed around the co-crystallized ligand. Finally, docking was performed via AutoDock Vina [18] while 
visualization of docking results was done via Chimera. The docking protocol was validated by redocking the co-crystallized ligand onto the molecular target and comparing the best generated binding pose with that of the cocrystallized ligand [19].

\section{RESULTS}

\section{Chemistry}

The new target 2-amino-4-aryl-6-substituted pyridine-3,5-dicarbonitrile derivatives (S1 - S4) were produced with good yield by one-pot multicomponent reactions as previously described [15]. Scheme 1 outlines the synthesis of the designed target compounds. The structure of the target compounds was completely identified by spectral data, as represented in the experimental section. In the IR spectra, characteristic bands at 3108, 2225 and $1623 \mathrm{~cm}^{-}$ ${ }^{1}$ was observed refereing to $\mathrm{N}-\mathrm{H}, \mathrm{C} \equiv \mathrm{N}$ and $\mathrm{C}=\mathrm{N}$ groups, respectively. In the ${ }^{1} \mathrm{H}-\mathrm{NMR}$ spectra, the presence of aromatic prorons at 7.1 - $7.55 \mathrm{ppm}$ and $\mathrm{NH}_{2}$ protons at $7.23 \mathrm{ppm}$ were clearly observed. Molecular ion peaks in the mass spectra provided additional verification for the structure of the newly synthesized pyridine derivatives.

\section{In vitro cell viability study}

In order to assess the possible cytotoxic effect of the synthesized pyridine derivatives, the in vitro cytotoxicity of the compounds (S1-S4), over a concentration range of $0.1-100 \mu \mathrm{M}$, was validated against six human cancer cell lines (HepG2, A549, MDA-MB-231, MCF-7, PC3, HELA). The cytotoxicity of 5-flurouracil (5-FU), a standard anticancer compound, was also determined under the same experimental condition for the purpose of comparison. The $\mathrm{IC}_{50}$ values, expressed in $\mu \mathrm{M}$, of the newly synthesized compounds along with that of 5-FU are represented in Table 2 .

It was obvious that all the synthesized compounds exerted a dose-dependent cytotoxic effects against PC3, HepG2, MDA-MB-231 (except for S2), and HELA (except for S3) cancer cell lines. In particular, all the compounds under investigation showed a superior cytotoxic activity against PC3 cancer cell line, compared to the standard anticancer compound (5-FU). The $\mathrm{IC}_{50}$ values against PC3 cell line were $0.45,0.85,0.1$ and $0.56 \mu \mathrm{M}$ for S1, S2, S3 and S4, respectively. On the other hand, all the tested compounds showed inferior cytotoxic effects against breast adenocarcinoma (MDA-MB-231) compared to 5FU. The $\mathrm{IC}_{50}$ values were 28.2, 69.2 and $81.3 \mu \mathrm{M}$ for S1, S3 and S4 vs. $0.49 \mu \mathrm{M}$ for 5-FU. Most importantly, 5-FU and all tested compounds exhibited poor or no cytotoxic activities against A549 or MCF-7 cell lines.

\section{Molecular docking}

Molecular docking was conducted to examine the possible binding interactions of the target compounds to their proposed CDK2 target. CDK2 was chosen as a target based on its potential role in controlling apoptosis and restricting cancer progression [1,3]. Consequently, targeting CDK2 might offer potential benefits for cancer therapy. Molecular docking was performed using AutoDock Vina, while visualization was done using Chimera.

Initially, the co-crystallized ligand was redocked into its molecular target, and the best proposed binding mode was compared to that of the cocrystallized ligand in order to validate our docking protocol (Figure 1). Results of the redocking showed that there was an RMSD value of $1.047 \AA$ $(<2 \AA)$ between the original co-crystal ligand position and the best generated docked pose, indicating the validity of our docking protocol [20].

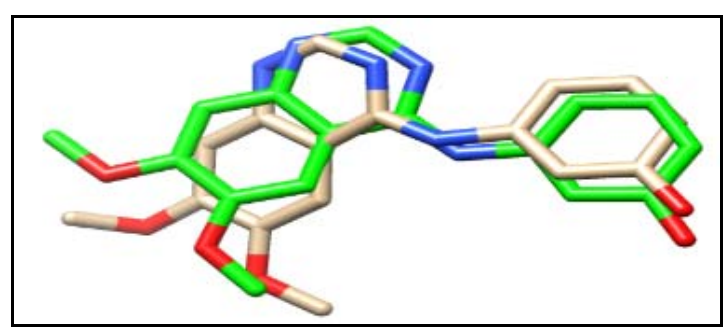

Figure 1: Docking validation by redocking the cocrystal ligands (Green color) to their corresponding receptors. Gray sticks represent the docked pose

Table 2: In vitro cytotoxicity activities of the tested compounds (S1-S4) against various cancer cell lines

\begin{tabular}{lcccccc}
\hline Comp. & HepG2 & MDA-MB-231 & Hela & PC3 & A549 & MCF-7 \\
\hline S1 & 15.8 & 28.2 & 2.82 & 0.45 & 100 & 100 \\
S2 & 0.2 & 100 & 1.2 & 0.85 & 100 & 100 \\
S3 & 0.261 & 69.2 & 100 & 0.1 & 100 & 100 \\
S4 & 0.242 & 81.3 & 74.1 & 0.56 & 100 & 100 \\
5-FU & 0.233 & 0.49 & 100 & 7.49 & 100 & 100 \\
\hline
\end{tabular}


The binding modes of the synthesized pyridine derivative was analyzed to interpret their biological results and to gain further insight into the binding orientations and the activity of the new compounds (Figure 2). The X-ray crystallographic CDK2 enzyme substrate (PDB ID: 1DI8) being complexed with the reference ligand; 5-flourouracil, revealed the presence of two hydrogen bonds with LEU83 and LYS33. Interestingly, the presented docking study confirmed comparable binding modes between the designed compounds and the docked molecules. The binding energy and the binding mode of the biologically active synthesized compounds are summarized in Table 3.

Molecular docking analysis of the new compounds revealed that compounds S1, S2 and $\mathrm{S} 4$ retained at least one essential $\mathrm{H}$-bonds with either LEU83 or LYS33, when compared with 5-fluorouracil. Furthermore, whereas compounds S1 and S3 forms only one $\mathrm{H}$-bond with LEU83 or ASP145, respectively, and with different binding mode than that of the lead compound, they showed higher antitumor activity against PC3 cancer cell line.

Compound S2 showed $-9.4 \mathrm{~kJ} \mathrm{~mol}^{-1}$ binding energy, forming two amino acid hydrogen bonds with LYS33 and GLN131 and exhibited superior antitumor efficacy against PC3 and Hela cancer cells when compared to the ligand reference. Similarly, Compound S4 shows $-9.5 \mathrm{~kJ} \mathrm{~mol}^{-1}$ binding strength, forms four hydrogen bonds with amino acid and showed potent antitumor activities against PC3 and Hela cancer cells compared to the ligand reference.

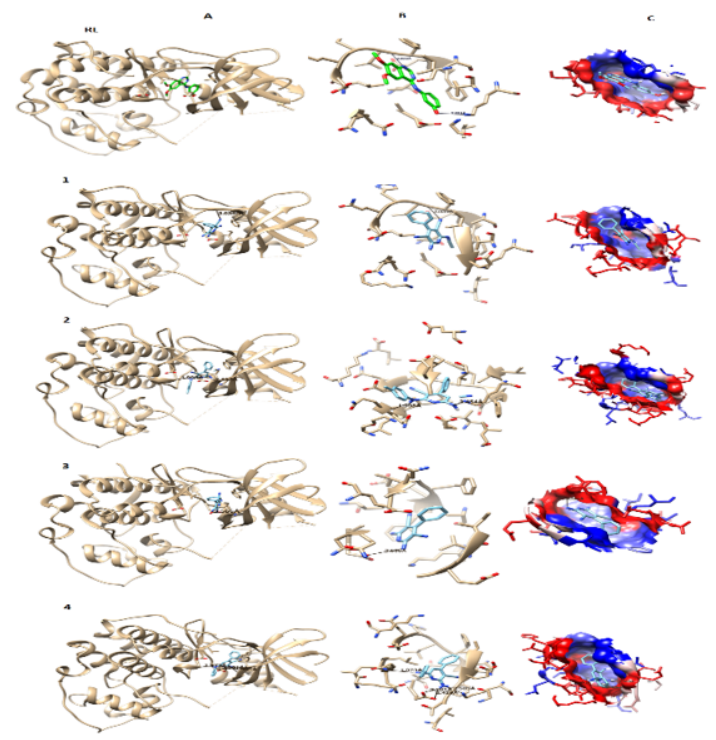

Figure 2: Interaction of the tested compounds and reference ligand $(\mathrm{RL})$ with $\mathrm{CDK} 2$ protein. A) 3D interaction, $\mathrm{B}$ ) $\mathrm{H}$-bond formation, and $\mathrm{C}$ ) hydrophobic interaction represented by blue color

\section{DISCUSSION}

Despite advances in diagnosis and care over the last 40 years, cancer remains a significant global public health problem. The search for new drug entities with anticancer activities is a complex and costly task, with only a few new compounds finding their way to the market, after being clinically tested. High Throughput Screening (HTS) is a critical method for detecting initial lead compounds for a particular target disease [21]. Unfortunately, HTS shows a high failure rate and, in many situations, fails to detect ideal viable drug leads.

Table 3: Results of the docking study of the test compounds against CDK2 binding pocket

\begin{tabular}{|c|c|c|c|c|c|}
\hline \multirow{3}{*}{ Comp. no. } & \multicolumn{4}{|c|}{$C D K 2$} & \multirow{3}{*}{ Hydrophobic interaction } \\
\hline & \multicolumn{2}{|l|}{$\begin{array}{l}\text { Energy of } \\
\text { free binding }\end{array}$} & \multicolumn{2}{|l|}{ H-Bond } & \\
\hline & $\Delta G_{b}^{a}$ & No. & Amino acid & Length $\AA$ & \\
\hline 1 & -8.6 & 1 & LEU83 & 3.039 & $\begin{array}{c}\text { ILE10, LEU83, LEU134, LEU148, PHE82, } \\
\text { VAL18, VAL64 }\end{array}$ \\
\hline 2 & -9.4 & 2 & $\begin{array}{l}\text { LYS33 } \\
\text { GLN131 }\end{array}$ & $\begin{array}{l}3.454 \\
1.998\end{array}$ & $\begin{array}{l}\text { ILE10, LEU83, LEU133, LEU134, LEU148, } \\
\text { LEU298, PHE82,VAL18, VAL30, VAL64 }\end{array}$ \\
\hline 3 & -8.3 & 1 & ASP145 & 3.566 & ILE10, VAL18, VAL30, VAL64 \\
\hline 4 & -9.5 & 4 & $\begin{array}{c}\text { LYS33 } \\
\text { ASP145 } \\
\text { ASP145 } \\
\text { GLN131 }\end{array}$ & $\begin{array}{l}3.503 \\
2.429 \\
2.501 \\
1.973\end{array}$ & $\begin{array}{c}\text { ILE10, LEU83, LEU134, LEU148, PHE82, } \\
\text { VAL18, VAL64 }\end{array}$ \\
\hline $\begin{array}{l}\text { Reference } \\
\text { ligand }\end{array}$ & -8.3 & 2 & $\begin{array}{l}\text { LYS33 } \\
\text { LEU83 }\end{array}$ & $\begin{array}{l}2.831 \\
2.803\end{array}$ & $\begin{array}{l}\text { ILE10, LEU83, LEU133, LEU134, LEU148, } \\
\text { LEU184, PHE82VAL18, VAL64 }\end{array}$ \\
\hline
\end{tabular}


Molecular docking (an alternative HTS method) is a popular component of the drug discovery process and provides a straightforward way of evaluating possible binders from large chemical libraries with minimal costs [22].

Cyclin dependent kinase 2 (CDK2) is a wellknown therapeutic target for conquering cancer [23]. In this study, we used a one-pot multicomponent condensation reaction to synthesize novel pyridine derivatives, and we investigated their efficiency as plausible inhibitors for CDK2 enzyme. All the compounds were efficiently synthesized with good yield. In addition, all the synthesized compounds showed remarkable cytotoxic activity against various tumor cell lines, particularly, prostate cancer (PC3) cell line compared to a reference compound, 5-fluorouracil (IC $50.49 \mu \mathrm{M})$. Furthermore, molecular docking studies in the CDK2 active site disclosed the efficient binding of the synthesized compounds to CDK2 active site, which was closely correlated with the cytotoxic potential of the newly synthesized compounds.

The MTT assay has been extensively used in cytotoxicity experiments to screen newly synthesized compounds for anticancer potential [16]. In this study, all the synthesized compounds demonstrated significant cytotoxic effect against various tumor cell lines, particularly, prostate cancer (PC3) cell line with an $\mathrm{IC}_{50}$ ranged from 0.1 to $0.85 \mu \mathrm{m}$, compared to a reference compound, 5-fluorouracil ( $\left.\mathrm{IC}_{50} 7.49 \mu \mathrm{m}\right)$. The remarkable cytotoxic activities of the tested compounds when compared to 5-FU could be attributed to (i) the presence of an aryl hydrophobic group in position-4 of the pyridine ring which enhances binding energy via occupation of the unoccupied hydrophobic region binding pocket, and (ii) the presence of $\mathrm{CN}$ and $\mathrm{NH}$ groups at phenyl pyridine ring.

One of the most challenging computational chemistry tasks is to predict protein/ligand binding affinity. In this study, molecular docking revealed efficient binding interactions of the target compounds to their proposed CDK2 target (Figure 2). Furthermore, analysis of the binding modes of the synthesized pyridine derivative demonstrated that compounds S2 and S4 showed higher binding energies, compared to the ligand reference (Table 3). Collectively, these results suggest that the superior antitumor efficacy of compounds S2 and S4 against PC3 and Hela cancer cells, compared to the ligand reference, is closely correlated with the efficient binding of these compounds and the docked molecules.

\section{CONCLUSION}

Using a one-pot multicomponent condensation process, novel 2-amino-4-aryl-6-substituted pyridine-3,5-dicarbonitrile derivatives have been successfully synthesized. All the synthesized pyridine derivatives exhibit remarkable in vitro cytotoxic activities against various cancer cell lines. In addition, molecular docking results suggest that the synthesized pyridine derivatives might represent plausible CDK2 inhibitors for potential application in cancer therapy. Nevertheless, pharmacological studies are required to confirm their antitumor efficacy in vivo.

\section{DECLARATIONS}

\section{Acknowledgement}

This research was funded by Scientific Research Deanship at University of Ha'il, Saudi Arabia through Project no. RG-20 117.

\section{Conflicts of interest}

No conflict of interest is associated with this work.

\section{Contribution of authors}

We declare that this work was done by the authors named in this article and all liabilities pertaining to claims relating to the content of this article will be borne by the authors. Amr Abu Lila, Marwa Abdallah, El-Sayed Khafagy and Shadeed Gad designed the study and supervised the data collection. Mohamed Omran and Kareem Younes analyzed and interpreted the data. Tamer Shehata and Mahmoud Soliman prepared and reviewed the manuscript for publication. All authors have read and approved the manuscript.

\section{Open Access}

This is an Open Access article that uses a funding model which does not charge readers or their institutions for access and distributed under the terms of the Creative Commons Attribution License (http://creativecommons.org/licenses/by/ 4.0) and the Budapest Open Access Initiative (http://www.budapestopenaccessinitiative.org/rea d), which permit unrestricted use, distribution, and reproduction in any medium, provided the original work is properly credited. 


\section{REFERENCES}

1. Ding L, Cao J, Lin W, Chen H, Xiong X, Ao H, Yu M, Lin $J$, Cui Q. The Roles of Cyclin-Dependent Kinases in Cell-Cycle Progression and Therapeutic Strategies in Human Breast Cancer. Int J Mol Sci 2020; 21(6): 1960.

2. Duronio RJ, Xiong Y. Signaling pathways that control cell proliferation. Cold Spring Harb Perspect Biol 2013; 5(3): a008904-a.

3. Łukasik P, Załuski M, Gutowska I. Cyclin-Dependent Kinases (CDK) and Their Role in Diseases Development-Review. Int J Mol Sci 2021; 22(6): 2935.

4. Mazumder S, DuPree EL, Almasan A. A dual role of cyclin $E$ in cell proliferation and apoptosis may provide a target for cancer therapy. Curr Cancer Drug Targets 2004; 4(1): 65-75.

5. Kolupaeva V, Basilico C. Overexpression of cyclin E/CDK2 complexes overcomes FGF-induced cell cycle arrest in the presence of hypophosphorylated $R b$ proteins. Cell Cycle 2012; 11(13): 2557-2566.

6. Mikhail S, Albanese C, Pishvaian MJ. Cyclin-Dependent Kinase Inhibitors and the Treatment of Gastrointestinal Cancers. Am J Pathol 2015; 185(5): 1185-1197.

7. Guimarães DSM, de Sousa Luz LS, do Nascimento $S B$, Silva LR, de Miranda Martins NR, de Almeida HG, de Souza Reis V, Maluf SE, Budu A, Marinho JA, et al. Improvement of antimalarial activity of a 3-alkylpiridine alkaloid analog by replacing the pyridine ring to a thiazole-containing heterocycle: Mode of action, mutagenicity profile, and Caco-2 cell-based permeability. Eur J Pharm Sci 2019; 138: 105015.

8. Dayam R, Sanchez T, Clement O, Shoemaker R, Sei S, Neamati N. $\beta$-Diketo Acid Pharmacophore Hypothesis. 1. Discovery of a Novel Class of HIV-1 Integrase Inhibitors. J Med Chem 2005; 48(1): 111-120.

9. Mohamed EA, Ismail NSM, Hagras M, Refaat $H$. Medicinal attributes of pyridine scaffold as anticancer targeting agents. Future J Pharm Sci 2021; 7(1): 24.

10. Slyusarenko El, Gorodetskova NP, Pesotskaya GV, Levchenko ES, Mogilevich SE, Luk'yanchuk VD. Pyridine derivatives possessing hypoglycemic and analgesic activity. Pharm Chem J 1989; 23(9): 739-743.

11. Bozdağ-Dündar O, Özgen Ö, Menteşe A, Altanlar N, Atıı $O$, Kendi E, Ertan R. Synthesis and antimicrobial activity of some new thiazolyl thiazolidine-2,4-dione derivatives. Bioorg Med Chem 2007; 15(18): 6012-6017.
12. El-Naggar M, Almahli H, Ibrahim HS, Eldehna WM, Abdel-Aziz HA. Pyridine-Ureas as Potential Anticancer Agents: Synthesis and In Vitro Biological Evaluation. Molecules 2018; 23(6): 1459.

13. Wu F, Zhou C, Yao Y, Wei L, Feng Z, Deng L, Song Y. 3(Piperidin-4-ylmethoxy)pyridine Containing Compounds Are Potent Inhibitors of Lysine Specific Demethylase 1. J Med Chem 2016; 59(1): 253-263.

14. Byth KF, Geh C, Forder CL, Oakes SE, Thomas AP. The cellular phenotype of AZ703, a novel selective imidazo[1,2-\&lt;em\&gt;a\&lt;/em\&gt;]pyridine cyclindependent kinase inhibitor. Mol Cancer Ther 2006; 5(3): 655.

15. Mahmoud NFH, El-Sewedy A. Multicomponent Reactions, Solvent-Free Synthesis of 2-Amino-4-aryl-6substituted Pyridine-3,5-dicarbonitrile Derivatives, and Corrosion Inhibitors Evaluation. J Chem 2018; 2018 : 7958739.

16. Al Saqr A, Wani SU, Gangadharappa HV, Aldawsari MF, Khafagy E-S, Lila ASA. Enhanced Cytotoxic Activity of Docetaxel-Loaded Silk Fibroin Nanoparticles against Breast Cancer Cells. Polymers 2021; 13(9): 1416.

17. Pedretti A, Villa L, Vistoli G. VEGA--an open platform to develop chemo-bio-informatics applications, using plugin architecture and script programming. J Comput Aided Mol Des 2004; 18(3): 167-173.

18. Dacanay FND, Ladra MCJA, Junio HA, Nellas RB. Molecular Affinity of Mabolo Extracts to an Octopamine Receptor of a Fruit Fly. Molecules 2017; 22(10): 1677.

19. Tantawy MA, Sroor FM, Mohamed MF, El-Naggar ME, Saleh FM, Hassaneen HM, Abdelhamid IA. Molecular Docking Study, Cytotoxicity, Cell Cycle Arrest and Apoptotic Induction of Novel Chalcones Incorporating Thiadiazolyl Isoquinoline in Cervical Cancer. Anticancer Agents Med Chem 2020; 20(1): 70-83.

20. Kolb P, Irwin JJ. Docking screens: right for the right reasons? Curr Top Med Chem 2009; 9(9): 755-770.

21. Hughes JP, Rees S, Kalindjian SB, Philpott KL. Principles of early drug discovery. Br J Pharmacol 2011; 162(6): 1239-1249.

22. de Ruyck J, Brysbaert G, Blossey R, Lensink MF. Molecular docking as a popular tool in drug design, an in silico travel. Adv Appl Bioinform Chem 2016; 9: 1-11.

23. Shapiro GI. Cyclin-dependent kinase pathways as targets for cancer treatment. J Clin Oncol 2006; 24(11): 17701783. 